\title{
Formação de interlocutores de uma criança com paralisia cerebral para o uso da comunicaçáo alternativa $^{1}$
}

\author{
Mariana Gurian Manzini ${ }^{a}$, Claudia Maria Simóes Martinez ${ }^{\mathrm{b}}$, Gerusa Ferreira Lourenço ${ }^{\mathrm{b}}$, \\ Bárbara de Brito Oliveira ${ }^{a}$ \\ ${ }^{a}$ Universidade Federal de São Carlos - UFSCar, São Carlos, SP, Brasil.

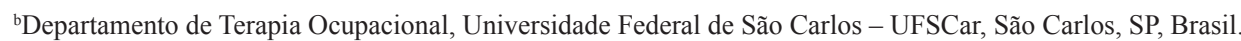

\begin{abstract}
Resumo: Introdução: Crianças com necessidades complexas de comunicação se beneficiam da comunicação alternativa quando seus interlocutores fazem bom uso desse recurso. Objetivo: Descrever o processo de formação de interlocutores de uma criança com paralisia cerebral para o uso da comunicação alternativa. Método: Os participantes foram: uma criança com paralisia cerebral e seus interlocutores nos respectivos ambientes de atuação: professora (escola), mãe (casa) e fisioterapeuta (clínica). Foram utilizados instrumentos para caracterização dos participantes, análise da dinâmica de mímica, seleção das figuras, análise das filmagens e percepção dos participantes sobre a implementação da comunicação alternativa. A coleta e análise dos dados foram organizadas em cinco fases: conhecimento das habilidades comunicativas, formação teórica e prática, confecção da prancha de comunicação e avaliação da formação. Resultados: Na formação teórica, a sensibilização permitiu aos interlocutores compreender a dificuldade diária da criança para se comunicar sem o uso da comunicação oral, o que resultou no decorrer das sessões de formação prática no aumento das estratégias ofertadas pelos interlocutores durante a realização das atividades, aumentando, assim, a chance de resposta da criança com o uso das figuras de comunicação alternativa. Conclusão: A formação de três interlocutores de uma criança com paralisia cerebral favoreceu que a comunicação alternativa fosse implementada em três contextos de desenvolvimento da criança. O suporte teórico-prático ofertado aos interlocutores em três contextos naturais podem proporcionar maior independência e participação social de uma criança com paralisia cerebral não falante na realização das atividades de vida diária.
\end{abstract}

Palavras-chave: Auxiliares de Comunicação para Pessoas com Deficiência, Paralisia Cerebral, Terapia Ocupacional.

\section{Alternative communication training of interlocutors for children with cerebral palsy}

\begin{abstract}
Introduction: Children with complex communication needs benefit from alternative communication when their interlocutors make good use of this resource. Objective: Describe the process of alternative communication training of interlocutors for children with cerebral palsy. Method: The participants were children with cerebral palsy and their interlocutors in the respective environments: teacher (school), mother (home) and physiotherapist (clinic). We used instruments to characterize the participants, analysis of mime dynamics, selection of figures, analysis of the footage and perception of participants on the implementation of alternative communication. The data collection and analysis were organized in five stages: knowledge of communicative skills, theoretical and practical training, preparation of the communication board, and evaluation of the training. Results: In the theoretical formation, the sensitization allowed the interlocutors to understand the child's daily difficulty to communicate without the use of oral communication. This resulted, in the course of the practical training sessions, in the increase of the strategies offered by the interlocutors during the activities, therefore, increasing the child's chance of responding with the use
\end{abstract}

Autor para Correspondência: Mariana Gurian Manzini, Universidade Federal de São Carlos, Rodovia Washington Luiz, Km 235, CP 676, CEP 13565-905, São Carlos, SP, Brasil, e-mail: mariana_gurian@yahoo.com.br 
of alternative communication figures. Conclusion: The training of three interlocutors for a child with cerebral palsy favored that alternative communication in three contexts of the child's development. The theoretical-practical support offered to the interlocutors in three natural contexts can provide greater independence and social participation of a child with non-speaking cerebral palsy in the accomplishment of daily activities.

Keywords: Communication Aids for People with Disabilities, Cerebral Palsy, Occupational Therapy.

\section{Introdução}

A Comunicação Suplementar e/ou Alternativa (CSA) é caracterizada pelo uso de gestos, expressôes faciais e corporais, símbolos gráficos, fotos, objetos, voz digitalizada ou sintetizada, a qual tem por finalidade promover a comunicação face a face de indivíduos com severos distúrbios na comunicação (VIANNA; GRECA; SILVA, 2014; KRÜGER et al., 2015).

O terapeuta ocupacional pode utilizar a CSA como uma estratégia de intervenção que não se restringe apenas à implementação de recursos (PELOSI, 2005, 2009; MANZINI; ASSIS; MARTINEZ, 2013).

Esse profissional presta serviços em CSA de forma a: avaliar o sujeito considerando suas habilidades físicas, cognitivas, sensoriais e emocionais; traçar o perfil ocupacional do paciente; identificar as ocupaçôes e as atividades necessárias para que a CSA desenvolva-se; identificar o parceiro de comunicaçáo; selecionar o recurso mais adequado; capacitar os parceiros de comunicação; e acompanhar o desenvolvimento do processo com constantes reavaliaçóes (MANZINI; ASSIS; MARTINEZ, 2013, p. 61).

A literatura afirma que os recursos de CSA podem impactar positivamente as atividades realizadas no cotidiano (NUNES; DELGADO; WALTER 2011), proporcionar aquisiçáo e desenvolvimento de habilidades comunicativas funcionais (LIGHT; MCNAUGHTON, 2013, 2014), favorecer participação nas atividades sociais e a expressão de necessidades, desejos e troca de informaçôes (KENNEDY, 2010; MANZINI; MARTINEZ; ALMEIDA, 2015), beneficiar uma comunicação independente, autônoma e funcional (CESA; MOTA, 2015; LIGHT; MCNAUGHTON, 2012, 2015), estabelecer e manter relaçóes sociais (PELOSI, 2009), promover melhoras na qualidade de vida (BRASIL, 2013).

Nesta perspectiva, é essencial que esses recursos sejam utilizados em todos ambientes sociais que essas crianças estejam envolvidas. Tetzchner (2009) afirmou a necessidade de um ambiente competente, destacando que os usuários de CSA, a família e os profissionais da Saúde e Educação devem compreender o significado e a função dos recursos de CSA, bem como, adquirir conhecimentos teóricos e práticos sobre essa área.

Crianças com paralisia cerebral podem apresentar desordens de natureza comunicativa (ROSENBAUM et al., 2007; BAX et al., 2005). Esse público-alvo beneficia-se de programas de intervenção de CSA direcionados à orientação, capacitação e instrumentalização do usuário e de seus interlocutores (DUTRA; FAGUNDES; SCHIRMER, 2007; MANZINI, 2013).

Importante destacar alguns estudos que trabalharam com a formaçáo de interlocutores por meio do uso da CSA com crianças com paralisia cerebral: com famílias no ambiente clínico (NUNES; DELGADO; WALTER, 2011; MANZINI, 2013; PIRES; LIMONGI, 2007), com professores no ambiente escolar (ROCHA; DELIBERATO; ARAÚJO, 2015; SILVA, 2011; COSTIGAN; LIGHT, 2010) e com terapeutas no ambiente terapêutico (DELIBRATO, 2010; BORTAGARAI; RAMOS-SOUZA, 2012). Grande parte dos estudos aponta a importância de um familiar participar dos procedimentos de intervenção empregados durante a implementação dos recursos de comunicação alternativa. Os resultados dos estudos acima também revelaram a necessidade dos profissionais da área da saúde e da educação utilizarem a comunicação alternativa com crianças com paralisia cerebral, salientando a necessidade desses profissionais adquirirem conhecimentos teóricos e práticos para utilizar os recursos de CSA.

Justifica-se que, embora a literatura examinada traga pesquisas que empregaram a implementação da CSA com famílias, professores e profissionais $\mathrm{da}$ saúde, ainda não foram desenvolvidos programas com a participação da família, da escola e de terapeutas em um mesmo momento do ciclo de vida de crianças com paralisia cerebral náo verbais. Os estudos se dedicaram a analisar estas temáticas com o foco na própria criança, isoladamente de seus contextos de desenvolvimento.

\section{Objetivo}

Descrever o processo de formação de interlocutores de uma criança com paralisia cerebral para o uso da comunicação alternativa. 


\section{Método}

Pesquisa descritiva caracterizada pelo uso da abordagem qualitativa (MINAYO, 2013) para descrever os procedimentos teóricos e práticos adotados no processo de formação de três interlocutores de uma criança com paralisia cerebral não verbal e avaliar os procedimentos de intervenção empregados durante a implementação do "Programa Individualizado de Comunicação Alternativa para crianças com Paralisia Cerebral não verbais, familiares, profissionais da área da saúde e da educaçáo" (MANZINI; MARTINEZ; ALMEIDA, 2015) e intitulado como "Comunica_PC" (MANZINI, 2015).

\subsection{Considerações éticas}

O presente estudo teve o parecer favorável pelo Comitê de Ética ${ }^{2}$. Os participantes da pesquisa receberam e assinaram o termo de consentimento livre e esclarecido com todas as informaçôes sobre o projeto.

\subsection{Participantes e local}

Participaram da pesquisa uma criança ${ }^{3}$ com 12 anos e com diagnóstico de paralisia cerebral não verbal e seus interlocutores nos respectivos ambientes de atuaçáo: professora (contexto escolar), mãe (contexto domiciliar) e fisioterapeuta (contexto clínico). A Tabela 1 apresenta as características dos participantes da pesquisa.

A Tabela 2 caracteriza as habilidades comunicativas da criança na percepção de cada interlocutor.

\subsection{Instrumentos de coleta de dados}

Protocolo de caracterizaçáo dos participantes: identifica as características dos participantes quanto ao gênero, idade, grau de escolaridade, profissão e diagnóstico. Foi elaborado pela pesquisadora e composto por quatro perguntas abertas e de múltipla escolha (MANZINI, 2015).

Questionário sobre as habilidades comunicativas das crianças: identifica as habilidades comunicativas utilizadas pela criança antes da intervençáo a partir da percepção da mãe, profissionais da área da saúde e educação. Composto por três questóes de múltipla escolha sobre a caracterização da comunicação da criança (uso de gestos, expressóes corporais e faciais); parceiros de comunicação (familiares, amigos, professores); o que ela comunica (dor, medo, tristeza, felicidade, vontades) e uma pergunta aberta sobre a rotina da criança (MANZINI, 2013).

Roteiro para analisar a percepçáo dos participantes sobre a implementaçáo da comunicaçáo alternativa: composto por quatro perguntas abertas que analisam: a percepção dos interlocutores sobre a importância da implementação da CSA; as habilidades que a criança adquiriu por meio do programa de intervenção; os pontos

Tabela 1. Características dos participantes da pesquisa.

\begin{tabular}{cccl}
\hline Participante & Idade & Contexto Estudado & Características dos participantes \\
\hline \multirow{2}{*}{ Criança } & \multirow{2}{*}{12 anos } & Domiciliar, escolar e clínico & Paralisia Cerebral não oralizada \\
\cline { 4 - 4 } Mãe & \multirow{2}{*}{42 anos } & Domiciliar & Ensino Médio Incompleto \\
\cline { 4 - 4 } Professora & \multirow{2}{*}{45 anos } & \multirow{2}{*}{ Escola especial } & Do lar \\
\hline Fisioterapeuta & 33 anos & Clínica & Mestrado em Educação Especial \\
\hline
\end{tabular}

Tabela 2. Caracterização das habilidades comunicativas da criança na percepção de cada interlocutor.

\begin{tabular}{cccc}
\hline Características & Mãe & Professora & Fisioterapeuta \\
\hline Habilidades comunicativas & $\begin{array}{c}\text { Expressões faciais, } \\
\text { movimentos corporais, } \\
\text { sorriso e balbucios }\end{array}$ & $\begin{array}{c}\text { Expressões faciais, } \\
\text { movimentos corporais, } \\
\text { sorriso e balbucios }\end{array}$ & $\begin{array}{c}\text { Expressões faciais, } \\
\text { movimentos corporais e } \\
\text { sorriso }\end{array}$ \\
\hline Parceiros de comunicação & $\begin{array}{c}\text { Familiares, profissionais } \\
\text { da saúde e educação }\end{array}$ & $\begin{array}{c}\text { Familiares, profissionais } \\
\text { da saúde e educação }\end{array}$ & $\begin{array}{c}\text { Familiares, profissionais } \\
\text { da saúde e educação }\end{array}$ \\
\hline Necessidades expressadas & $\begin{array}{c}\text { Dor, tristeza, felicidade e } \\
\text { vontade de ir ao banheiro }\end{array}$ & Dor, tristeza e felicidade & Dor, tristeza e felicidade \\
\hline Atendimentos realizados & $\begin{array}{c}\text { Terapia ocupacional, } \\
\text { fisioterapia e equoterapia }\end{array}$ & & \\
\hline
\end{tabular}


positivos e negativos do programa de intervenção e os aspectos da intervenção que poderiam ser modificados (MANZINI, 2013).

Protocolo para seleçáo das figuras para compor a prancha de comunicaçáo: elaborado por Manzini (2013) baseado nos itens que compóem a Medida Canadense de Terapia Ocupacional COPM (LAW et al., 2009) e o Picture Exchange Communication System - PECS (BONDY; FROST, 2001). O protocolo ficou estruturado por três áreas e subáreas: autocuidado (vestuário, alimentação, banho e higiene); produtividade (o brincar) e lazer (recreação e socialização). Para cada subárea, no mínimo, três figuras podem ser selecionadas para compor a prancha de comunicação, não sendo estabelecido um número máximo de itens (MANZINI, 2013).

Protocolo para análise da dinâmica de mímica: elaborado pela pesquisadora, descreve e analisa a dinâmica de mímicas por meio de cinco questóes abertas, referentes à: informação transmitida pelo interlocutor na dinâmica, estratégias utilizadas para transmitir a informação, uso de fala durante a dinâmica, dificuldades e facilidades relatadas pelos participantes durante a vivência da dinâmica (MANZINI, 2015).

\subsection{Materiais e equipamentos}

Computador, filmadora, máquina fotográfica, computador, folha de EVA, papel contact, espiral, folha sulfite, caderno para registro contínuo de informaçóes, figuras e os símbolos gráficos do software Boardmaker.

\subsection{Procedimentos de coleta e análise de dados}

A coleta e análise dos dados foram compostas por 05 fases, as quais serão detalhadas a seguir:

\section{Fase 1}

Objetivo: Avaliação das habilidades comunicativas da criança e as características de cada participante. Instrumento de coleta: Protocolo de caracterização dos participantes e roteiro de entrevista das habilidades comunicativas das crianças. Análise realizada: Caracterização dos participantes e descrição das habilidades comunicativas da criança antes da intervenção. Quantidade de sessóes: Um encontro de pesquisa de 30 minutos com cada interlocutor em seus respectivos ambientes de atuação — professora (contexto escolar), máe (contexto domiciliar) e fisioterapeuta (contexto clínico).

\section{Fase 2}

Objetivo: Ofertar conhecimento teórico sobre a temática da Comunicação Suplementar e/ ou Alternativa e vivenciar a dinâmica de mímicas. Instrumento de coleta: Protocolo para análise da dinâmica de mímica. Análise realizada: Análise da dinâmica de mímicas realizada pelos interlocutores nos três contextos (domiciliar, escolar e clínico). Quantidade de sessôes: uma sessão de terapia ocupacional de 60 minutos com cada interlocutor em seus supracitados ambientes de atuaçáo.

\section{Fase 3}

Objetivo: Elaborar uma prancha de comunicação alternativa para cada contexto pesquisado, por meio dos pictogramas disponíveis no software Boardmaker, figuras selecionadas pelo Google e/ou fotos ${ }^{4}$. Para cada categoria do protocolo de seleçáo de figuras, eram selecionadas no mínimo 3 figuras, sendo que não foi estipulado um número máximo de figuras nem de páginas para cada prancha.

Quantidade de sessões: duas sessões de terapia ocupacional de 60 minutos com cada interlocutor em seus já citados ambientes de atuação.

\section{Fase 4}

Objetivo: Ensinar os interlocutores a utilizar as figuras de comunicação durante as atividades programadas e implementar a comunicação alternativa na escola, casa e clínica. Instrumento de coleta: Protocolo para análise das filmagens. Análise realizada: Análise da intervençáo no domicílio, na escola e na clínica.

Quantidade de sessões: 15 sessões de terapia ocupacional de 30 minutos com cada interlocutor em seus respectivos ambientes de atuação.

\section{Fase 5}

Objetivo: Avaliar a percepção dos interlocutores perante o programa de formação. Instrumento de coleta: Roteiro para analisar a percepção dos interlocutores sobre a CSA. Análise realizada: Análise da percepção dos interlocutores sobre a implementação do programa de formação.

Quantidade de sessôes: um encontro de pesquisa de 30 minutos com cada interlocutor em seus já mencionados ambientes de atuação.

Foram realizadas as transcriçóes na íntegra das filmagens de todas as fases e incorporados a estes dados as informaçóes coletadas por meio do registro contínuo de informaçóes. Os encontros foram planejados de acordo com a disponibilidade dos participantes e aconteceram na seguinte ordem: escola, clínica e casa. As sessóes ocorreram uma vez por semana com duração aproximada de 30 minutos. 
Ressalta-se que nos encontros de pesquisa não ocorreram intervençôes terapêuticas.

\section{Resultados}

O desenvolvimento da coleta de dados ocorreu num intervalo de 5 meses. Os resultados foram organizados em duas seçóes, considerando que o foco da presente pesquisa recai sobre o processo de formação dos interlocutores: (I) implementação de ações para formação dos interlocutores e (II) avaliação dos procedimentos de intervenção.

I - Implementação de açóes para formação dos interlocutores

A formação dos interlocutores foi dividida em: (a) formação teórica e (b) formação prática.

\section{a) Formação Teórica}

Este tópico compreende as seguintes informaçōes: dados referentes à aula expositiva sobre a temática da Comunicação Alternativa, ou seja, a dinâmica de mímicas, a reflexão sobre a dinâmica e a importância em utilizar recursos alternativos de comunicação.

Para descrever o relato dos interlocutores, este item foi subdividido em dois momentos: $1^{\mathrm{o}}$, a dinâmica de Mímicas e $2^{\circ}$, a reflexão sobre a dinâmica.

\section{$1^{\circ}$ Momento: Dinâmica de Mímicas}

A Dinâmica de Mímicas foi programada para os interlocutores vivenciarem o "transmitir e adivinhar uma informaçáo" por meio de uso de gestos, expressóes faciais e movimentos corporais, porém sem utilizar a fala oral.

A atividade aconteceu da seguinte maneira: (1) os participantes sortearam um papel com uma informação, (2) essa informação deveria ser transmitida para a pesquisadora por meio do uso de mímicas e (3) após a pesquisadora acertar a mensagem, ela também iria realizar essa atividade.

A atividade proposta foi realizada em 30 minutos e as informaçôes sorteadas pelos interlocutores foram:

- Mãe: "No passado as estrelas guiavam os viajantes" (frase);

- Professora: "Mulher escava neve para encontrar o carro soterrado nos Estados Unidos" (notícia);

- Fisioterapeuta: "Bolo de chocolate" (receita).

Para expressar a mensagem sorteada, os interlocutores utilizaram com frequência:
- Movimento corporal: recurso utilizado com o objetivo de expressar verbos de ação, caracterização na mensagem sorteada;

- Expressão facial: recurso utilizado com o intuito de transmitir se a adivinhação estava certa ou errada;

- Gesto representativo: recurso utilizado com o objetivo de expressar objetos concretos.

\section{Momento: Reflexão sobre a dinâmica}

Os participantes foram indagados sobre o que foi mais difícil na realização da atividade proposta: expressar ou compreender uma mensagem?

Mãe: Eu acho que os dois são difíceis, existe uma dificuldade dos dois lados. Mas, o mais dificil é falar do que adivinhar, porque você vai chutando e tem uma hora que você vai acerta. Agora você fala é mais difícil.

Fisioterapeuta: Eu acho que as duas coisas. Mas, também depende se a pessoa tiver mais facilidade para conseguir gesticular talvez fique mais fácil pra quem está tentando adivinhar. E outra eu penso assim também, depende do contexto, que nem a receita de bolo foi muito mais fácil. As vezes, eu tenho mais facilidade, mas fico imaginando o que eu vou fazer, como é que eu vou gesticular tal palavra. Eu tive essa sensação agora como a criança, porque realmente né, a gente às vezes tem assim aquela vontade que eles façam, que desenvolvam, $e$ às vezes a gente vai enchendo eles de pergunta e vai querendo mostrar tudo. Na hora da brincadeira, a pessoa dá várias informaçóes então a gente fica meio perdido. Então acho que é essa sensação que os alunos podem ter com a gente. Às vezes, a gente não se atenta a certos detalhes, ou seja, gente não deu oportunidade ou não esperou um tempo pra criança dar a resposta, e ai de repente já começamos a misturar várias coisas.

Professora: Então pra nós, a gente já tem linguagem né, a gente vai usar uma outra forma de linguagem, mas a gente já tem interpretação, a gente sabe que a gente tá fazendo, o recurso que a gente vai utilizar na questão de gesto, a gente pensa rápido, a gente consegue, não está tão abstrato, então não é difícil. Agora pra quem faz a leitura, eu acho que é mais dificil, porque aí você depende o que aquele objeto representa, acho que é bem mais difícil a interpretação.

Os interlocutores foram indagados também sobre o que acharam da dinâmica.

Mãe: $E$ difícil, mas nessa brincadeira a gente se colocou no lugar dele tanto eu quanto você. Como é dificil para ele querer mostrar ou falar alguma coisa e aí a gente não entende. 
Fisioterapeuta: Acho que foi uma situação desafiadora. Eu acho que ainda ficou um pouco mais fácil, pois não tinha nenhuma cobrança de detalhar tudo, mas se fosse pra detalhar a mensagem, eu acho que ficaria mais difícil. O legal disso é no final, quando a gente adivinha o que acontece, ai há uma satisfação total né independente de qualquer coisa.

Professora: Eu achei legal. A forma de você passar eu acho que não é tão difícil né, porque a gente já tem uma formação da linguagem. A questão é que às vezes a gente precisa ter um pouco mais de paciência para que a criança possa se comunicar.

Os interlocutores compreenderam a dificuldade de transmitir uma mensagem apenas com o uso de gestos, expressōes faciais, movimentos corporais, gestos indicativos e representativos. Além disso, desentendimentos, angústia, agonia e estresse também foram variáveis que surgiram no decorrer da dinâmica.

Nesta perspectiva, a dinâmica apresentou-se como um recurso de sensibilização na formação dos interlocutores. Eles compreenderam o objetivo da dinâmica e conseguiram vivenciar por meio do corpo em movimento que crianças com severos distúrbios na comunicação oral necessitam de recursos alternativos para se comunicar. Esta sensibilização proporcionada permitiu os interlocutores compararem esse momento com a dificuldade diária que eles têm de compreender o que a criança com paralisia cerebral quer expressar.

\section{b) Formação Prática}

A formação prática teve como objetivo geral ensinar os interlocutores a utilizar o software Boardmaker para selecionar pictogramas e confeccionar as pranchas de comunicação para cada contexto (familiar, escolar e clínico). Além disso, a formação prática consistiu em dar orientaçôes para os interlocutores ampliarem as habilidades comunicativas das crianças durante as atividades lúdicas.

Neste tópico foram analisados os dados referentes à construção e à implementação da prancha de comunicação alternativa com a mãe, professora e fisioterapeuta. A Tabela 3 descreve as figuras que foram selecionadas pelos três interlocutores.

As pranchas foram construídas por meio do protocolo de seleção de figuras, abordando as atividades de autocuidado, atividades produtivas e atividades de lazer. A mãe selecionou figuras relacionadas com a rotina da criança no ambiente familiar, ou seja, itens do centro de interesse da criança. Já a prancha elaborada pela professora foi construída por meio da rotina do ambiente escolar, selecionando itens referentes às situaçóes cotidianas vivenciadas na sala de aula desde a chegada do aluno na escola até a chegada da mãe na hora da saída. A prancha elaborada pelo fisioterapeuta foi construída por meio da rotina do ambiente clínico, acabando por escolher itens referentes às situaçóes cotidianas vivenciadas no ambiente de terapia.

Após a seleção das figuras, foi confeccionada uma prancha de comunicação para cada contexto. Cabe ressaltar que algumas figuras foram retiradas do software Boardmaker e outras retiradas do Google, as quais foram selecionadas por estarem mais próximas do cotidiano da criança participante do estudo.

A Tabela 4 mostra a caracterização das pranchas de comunicação alternativa confeccionadas.

A Figura 1 ilustra exemplos das pranchas confeccionadas. Importante ressaltar que as pranchas confeccionadas ficavam no ambiente de atuação de cada interlocutor. As figuras da prancha verde foram selecionadas pela máe, as figuras da prancha preta foram selecionadas pelo fisioterapeuta e as figuras $\mathrm{da}$ prancha vermelha foram selecionadas pela professora.

No segundo momento da formação ocorreu a instrução dos interlocutores (mãe, fisioterapeuta e professora) para o uso dos recursos confeccionados diretamente com a criança. A pesquisadora realizou orientações com o objetivo de estimular os interlocutores a oferecerem as atividades que seriam realizadas para as crianças.

Para utilizar as figuras de comunicação alternativa, os interlocutores receberam uma formação por meio dos passos a seguir:

$1^{\circ}$ Passo: Mostrar o objeto concreto para a criança. Ex.: urso de pelúcia;

20 Passo: Utilizar os estímulos (táteis, visuais, auditivos, verbais) que o objeto fornece para apresentar as características e função do mesmo. Ex.: o urso de pelúcia fornece estímulos táteis;

3o Passo: Comparar a figura de comunicaçáo com o objeto correspondente. Ex.: comparar o urso de pelúcia de brinquedo e a figura de um urso de pelúcia;

40 Passo: Oferecer a atividade para a criança por meio de auxílios (verbais, físicos, modelo) com o intuito que a criança pegue a figura de comunicação ou demonstre interesse pela atividade. Ex.: Aninha (nome fictício), agora nós vamos brincar com esse urso de pelúcia. 
Tabela 3. Figuras selecionadas para compor a prancha de cada contexto.

\begin{tabular}{|c|c|c|c|c|}
\hline Atividades & Categorias & $\begin{array}{l}\text { Centro de interesse no } \\
\text { ambiente domiciliar }\end{array}$ & $\begin{array}{l}\text { Centro de interesse no } \\
\text { ambiente escolar }\end{array}$ & $\begin{array}{l}\text { Centro de interesse no } \\
\text { ambiente clínico }\end{array}$ \\
\hline \multirow{4}{*}{$\begin{array}{l}\text { Atividades de } \\
\text { Autocuidado }\end{array}$} & Comida & Banana, iogurte & $\begin{array}{c}\text { Utensílios } \\
\text { (prato e colher) }\end{array}$ & 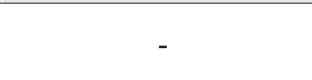 \\
\hline & Bebida & Leite, água & Caneca azul & - \\
\hline & Vestuário & $\begin{array}{l}\text { Cueca azul, camiseta } \\
\text { branca sem manga, } \\
\text { shorts, fralda }\end{array}$ & Fralda & - \\
\hline & Higiene Pessoal & $\begin{array}{c}\text { Bucha azul, shampoo } \\
\text { do Tralalá }\end{array}$ & $\begin{array}{l}\text { Escova de cabelo, } \\
\text { pente, escova e pasta de } \\
\text { dente, lavar as mãos }\end{array}$ & - \\
\hline $\begin{array}{l}\text { Atividades } \\
\text { Produtivas }\end{array}$ & $\begin{array}{l}\text { Brinquedos, } \\
\text { brincadeiras } \\
\text { ou objetos de } \\
\text { interesse }\end{array}$ & $\begin{array}{c}\text { Papai Noel, cachorro e } \\
\text { bichinho }\end{array}$ & $\begin{array}{l}\text { Bola, bolha de sabão, } \\
\text { urso de pelúcia, bexiga, } \\
\text { bola para pilates, tapete } \\
\text { sensorial, instrumentos } \\
\text { musicais (teclado, } \\
\text { chocalho, tambor), } \\
\text { rolos, standarte, } \\
\text { massinha, rádio }\end{array}$ & - \\
\hline \multirow{5}{*}{$\begin{array}{l}\text { Atividades de } \\
\text { Lazer }\end{array}$} & \multirow[t]{2}{*}{$\begin{array}{l}\text { Atividades } \\
\text { Preferidas }\end{array}$} & \multirow[t]{2}{*}{$\begin{array}{l}\text { Assistir TV, ficar de } \\
\text { barriga para baixo, } \\
\text { movimentar a cadeira } \\
\text { de rodas }\end{array}$} & $\begin{array}{l}\text { Mudança de decúbito } \\
\text { (sentado, deita), } \\
\text { cadeira de rodas, } \\
\text { cadeira escolar, piscina } \\
\text { de bolinhas, rede } \\
\text { de balanço, cama, } \\
\text { colchonete }\end{array}$ & \multirow{2}{*}{$\begin{array}{l}\text { Bola, instrumentos } \\
\text { musicais (violão, } \\
\text { tambor, chocalho), } \\
\text { jardim sensorial, } \\
\text { brinquedos de } \\
\text { estimulação tátil (água, } \\
\text { massinha, guache), } \\
\text { mudanças de decúbito } \\
\text { (rolo, bola para pilates, } \\
\text { tablado) }\end{array}$} \\
\hline & & & $\begin{array}{c}\text { Arrumar a mochila e } \\
\text { escrever no caderno da } \\
\text { criança }\end{array}$ & \\
\hline & $\begin{array}{l}\text { Lugares que } \\
\text { gosta de visitar }\end{array}$ & $\begin{array}{c}\text { Casa da avó, APAE e } \\
\text { equoterapia }\end{array}$ & 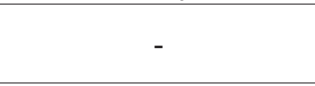 & - \\
\hline & Socialização & \multirow{2}{*}{$\begin{array}{c}\text { Mãe, pai, irmão, avó } \\
\text { e avô }\end{array}$} & & \multirow[b]{2}{*}{-} \\
\hline & $\begin{array}{l}\text { (pessoas que } \\
\text { conhece) }\end{array}$ & & & \\
\hline
\end{tabular}

Para nós brincarmos, você tem que pegar a figura e entregar na minha mão;

50 Passo: Fornecer tempo para a criança responder ao estímulo oferecido. Observar atentamente as reaçôes da criança (movimentos corporais, gestos indicativos, expressóes faciais, vocalizações).

Os passos citados acima foram realizados nos atendimentos como estratégia de intervenção com cada um dos interlocutores de modo a promover o uso funcional dos recursos de CSA.

Durante a formação, os interlocutores foram ensinados a utilizar uma figura por vez, ou seja, o interlocutor selecionava a atividade programada, retirava da prancha a figura e a colocava na placa individual com velcro. A criança demonstrava interesse apenas na figura relacionada com a atividade por meio do uso do sorriso e/ou das mãos para retirar a figura da placa individual. Cabe ressaltar que antes da introdução do recurso de CSA, a criança comunicava-se apenas por meio de olhares e sorriso.

Por meio do protocolo para análise das filmagens (MANZINI, 2015) e registro contínuo de informaçóes, foi possível identificar que no início dos encontros com pouco entendimento sobre o que seria realizado, os resultados indicaram que os interlocutores: (a) mãe: apresentou espontaneidade em utilizar os recursos; (b) fisioterapeuta: demonstrou receio em utilizar os recursos de maneira errada; (c) professora: apresentou muito interesse em aprender novas estratégias de intervenção.

No início da intervenção, ofereceram as atividades para a criança mecanicamente, ou seja, eles náo deram oportunidade para a criança expressar seus desejos. Ao longo dos encontros, a criança e os interlocutores foram apresentando satisfação no entendimento 
Tabela 4. Caracterização das pranchas de comunicação confeccionadas em conjunto entre pesquisadora e interlocutores.

\begin{tabular}{|c|c|c|c|}
\hline $\begin{array}{l}\text { Características das } \\
\text { Pranchas }\end{array}$ & Prancha para casa & Prancha para escola & Prancha para clínica \\
\hline Formato da prancha & \multicolumn{3}{|c|}{$\begin{array}{l}\text { Prancha vertical em formato A4 em espiral, com estímulos removíveis e placa para } \\
\text { uso individual com velcro }\end{array}$} \\
\hline Formato das figuras & \multicolumn{3}{|c|}{ Figuras $8 \times 8$ em EVA e velcro } \\
\hline $\begin{array}{l}\text { Técnica ensinada para } \\
\text { a criança demonstrar } \\
\text { interesse pela atividade }\end{array}$ & \multicolumn{3}{|c|}{ Uso do sorriso e das mãos para retirar a figura da placa individual } \\
\hline $\begin{array}{l}\text { Quantidade de figuras } \\
\text { em cada prancha }\end{array}$ & 26 & 33 & 13 \\
\hline \multirow{7}{*}{$\begin{array}{l}\text { Categorias selecionadas } \\
\text { pelos interlocutores para } \\
\text { montagem da prancha }\end{array}$} & Comida e bebida preferida & Atividades de rotina & Atividades de estimulação \\
\hline & Roupas & $\begin{array}{l}\text { Atividades de cuidado } \\
\text { pessoal }\end{array}$ & Atividades com as mãos \\
\hline & Higiene pessoal & Higiene pessoal & $\begin{array}{c}\text { Objetos de } \\
\text { posicionamento }\end{array}$ \\
\hline & Lugares & $\begin{array}{l}\text { Lugares para } \\
\text { posicionamento }\end{array}$ & \\
\hline & Atividades preferidas & $\begin{array}{l}\text { Atividades relacionadas } \\
\text { ao brincar }\end{array}$ & \\
\hline & Família & $\begin{array}{l}\text { Atividades de estimulação } \\
\text { sensorial }\end{array}$ & \\
\hline & & $\begin{array}{l}\text { Atividades de estimulação } \\
\text { auditiva }\end{array}$ & \\
\hline Posição da prancha & $\begin{array}{l}\text { Prancha disposta na } \\
\text { horizontal, próxima do } \\
\text { alcance da mão da criança }\end{array}$ & $\begin{array}{c}\text { Prancha disposta na } \\
\text { vertical próxima ao olhar } \\
\text { da criança }\end{array}$ & $\begin{array}{c}\text { Prancha disposta na } \\
\text { horizontal, próxima do } \\
\text { alcance da mão da criança }\end{array}$ \\
\hline $\begin{array}{l}\text { Estratégia para utilização } \\
\text { do recurso }\end{array}$ & $\begin{array}{c}\text { Uso de atividades } \\
\text { cotidianas, como } \\
\text { alimentação, lazer e } \\
\text { autocuidado } \\
\end{array}$ & $\begin{array}{c}\text { Uso de atividades } \\
\text { cotidianas como } \\
\text { alimentação, lazer e } \\
\text { autocuidado }\end{array}$ & $\begin{array}{c}\text { Uso de atividades } \\
\text { cotidianas como } \\
\text { alimentação, lazer e } \\
\text { autocuidado }\end{array}$ \\
\hline
\end{tabular}
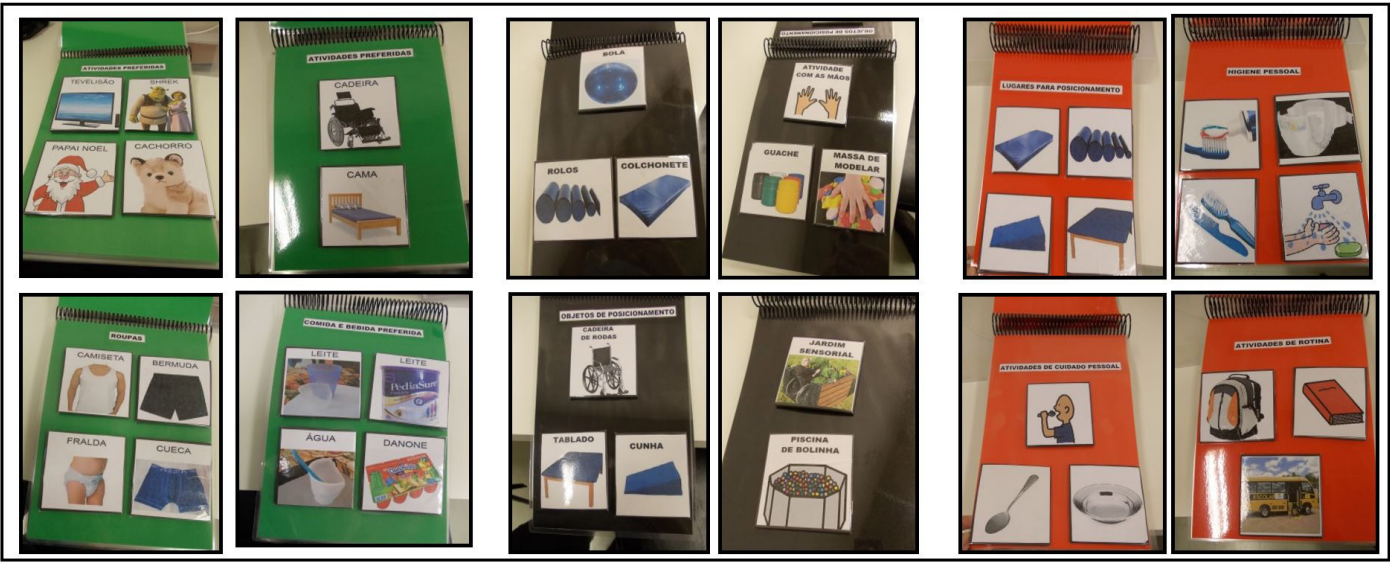

Figura 1. Pranchas confeccionadas para cada contexto estudado.

das estratégias, os interlocutores compreenderam as estratégias ensinadas e forneceram tempo para a criança responder ao estímulo oferecido. Percebeu-se também no decorrer das sessốes que quanto maior o número de estratégias ofertadas e ações realizadas pelos interlocutores, maior a chance de resposta da criança. No final da formação, os resultados mostraram que o uso dos recursos e das estratégias de realizar a troca da figura pelo seu objeto correspondente foi se efetivando.

\section{II - Avaliação dos procedimentos de formação}

O programa de comunicação alternativa foi avaliado pelos interlocutores e os dados foram aferidos por meio da transcrição do roteiro de percepção dos 
interlocutores sobre a implementação da comunicação suplementar e/ou alternativa

Os interlocutores foram questionados sobre a importância da pesquisa e da comunicação alternativa para a criança. As respostas foram positivas e diversificadas como pode ser notado a seguir.

Mãe: Eu acho que foi bom, porque é um estímulo a mais para ele né, coisas assim que ele não faz em casa. É bom as atividades serem aqui em casa por causa disso né, porque aqui em casa ele não faz atividades, ele fica só comigo, fica na cama não tem como variar com ele, é é bom por causa disso, porque são coisas novas para ele e para o Eduardo ${ }^{5}$ também.

Também vai ser melhor né ajuda ele ajuda eu também. Não sei se comentei com você isso, eu fiz uma vez com ele. Eu perguntei pra ele: você fez cocô?? Se sim fez você pisca senão não, ai ele pegou e piscou e ele tinha feito. Eu acho que ele tá prestando atenção mais atenção nas coisas.

Fisioterapeuta: Foi muito satisfatória, pois consegui perceber que ele teve ganhos na atenção, percep̧ção e reação de resposta mais rápida.

Professora: Eu vejo isso como um recurso que auxilia, naquele momento da atividade e que dá mais condiçôes para que ele e mais possibilidade de aumentar o conhecimento dele.

Os interlocutores foram questionados sobre os pontos negativos da pesquisa ou o que poderia ser melhorado.

Máe: Nenhum, não tem o que melhorar né. O legal é fazer na professora né, mas isso você já está fazendo.

Fisioterapeuta: Não teve. No comę̧o eu demorei a entender qual era seu objetivo, mas depois das aulas, da sua intervenção e capacitação eu comecei a entender. Uma coisa que eu quero agora é ler mais coisas sobre essa temática, a qual era desconhecida para mim.

Professora: Então assim, com relaçâo à pesquisa eu não achei nenhum ponto negativo, acho que foi pouco tempo, eu acho que deveríamos ter usado um momento específicol direcionado. Por exemplo, eu acho que podia ser assim mais direcionado para o dia a dia, a gente pegou muito a questão da atividade, do brincar e da música.

Agora, a gente tá nesse nivel de comunicação com ele né então nesse sentido eu acho que é útil se continuar, não pode se perder tudo o que conseguimos com ele na parte de comunicação.

\section{Discussão}

Crianças com paralisia cerebral podem apresentar severos distúrbios na comunicação oral, o que pode limitar sua comunicação com os interlocutores mais próximos, tais como pais e/ou familiares, profissionais da área da educação e da saúde (DELIBERATO, 2010; MANZINI, 2015).

Os diversos contextos diários frequentados pela criança, como casa, escola e terapias são microssistemas que promovem situaçóes interacionais básicas, sendo relaçóes face a face estáveis e significativas (DELIBERATO; SAMESHIMA, 2007), fatores sobre os quais se justifica a intervenção da área da comunicação suplementar proposta neste estudo.

Foi evidenciada a necessidade de atentar-se para o processo de formação de interlocutores de uma criança com paralisia cerebral e severos distúrbios na comunicação oral para o uso da comunicação alternativa. O estudo de Nunes, Delgado e Walter (2011) e Manzini (2013) evidenciaram falta de habilidade dos próprios interlocutores em reconhecer as necessidades e desejos das crianças não falantes. As autoras também apontaram que crianças com dificuldades de comunicação oral podem ser mal compreendidas e interpretadas pelos seus interlocutores mais próximos, necessitando assim de recursos alternativos de comunicação.

Nesta perspectiva, Deliberato (2010) discutiu a necessidade do interlocutor estar atento às diferentes emissôes orais e não orais e atento também à ocasiáo vivenciada para que se possa sistematizar o significado atribuído às habilidades expressivas das crianças com limitação na comunicação oral.

Ganham destaque na presente pesquisa os resultados encontrados na dinâmica de mímicas. Os interlocutores compreenderam a dificuldade de transmitir uma mensagem apenas com o uso de gestos, expressóes faciais e movimentos corporais. A pesquisa de Manzini, Martinez e Almeida (2015) corrobora esses resultados, pois mostrou que desentendimentos, angústias e estresse são variáveis presentes entre a comunicação da criança com paralisia cerebral e sua mãe.

Estudos apontam para a importância de inserir os interlocutores de crianças não oralizadas no processo de intervenção desde a etapa de confecção dos recursos de comunicação alternativa até a implementação direta com as crianças (WALTER; ALMEIDA, 2010; MANZINI, 2013). Essa participação é essencial, pois eles convivem cotidianamente com as crianças, conhecendo os desejos, os interesses e a 
rotina (MANZINI; MARTINEZ; ALMEIDA, 2015; ARAÚJO; BRACCIALLI; DELIBERATO, 2009).

Os procedimentos de intervenção mostraram-se exitosos, o que pode estar relacionado com o conceito de aprendizagem significativa, ou seja, a utilização de conhecimentos prévios foi determinante para as novas aprendizagens dos interlocutores (ALEGRO, 2008). O estudo mostra que o sucesso ocorreu, pois os interlocutores passaram de sujeitos passivos a compreender a posiçáo do outro e a se enxergarem como atores e parceiros legítimos de comunicação.

No processo de formação para o uso da comunicação alternativa, a participaçáo dos interlocutores mais próximos permite o desenvolvimento de uma parceria, a qual permite que as atividades realizadas no atendimento sejam reforçadas e mantidas em casa e generalizadas nos diferentes ambientes cotidianos (OMOTE, 2003). Por fim, a formação também deve proporcionar que os interlocutores sintam-se competentes para compreender as habilidades comunicativas das crianças desprovidas da fala oral (TETZCHNER, 2009).

Os recursos de comunicação suplementar e/ou alternativa somados à formação de interlocutores podem auxiliar na inclusão em ambientes sociais, na aquisiçáo de novas habilidades comunicativas, no aumento de interação durante as atividades cotidianas, no desenvolvimento da linguagem, na elevaçáo de autoestima e na qualidade de vida (LIGHT; MCNAUGHTON, 2012, 2014; PELOSI, 2005, 2009; TETZCHNER, 2009; KENNEDY, 2010).

\section{Conclusão}

O estudo teve como característica peculiar descrever a formação teórico-prática sobre a CSA para os principais interlocutores (mãe, professora, fisioterapeuta) de uma criança com paralisia cerebral nos ambientes mais comuns de cada interlocutor (casa, escola e clínica).

Os procedimentos de intervenção abriram espaço para que a CSA fosse implementada nas atividades cotidianas realizadas em três contextos de desenvolvimento vivenciados pela criança, o que poderá proporcionar maior independência e participaçáo social da criança com paralisia cerebral não falante.

Acredita-se que o processo de formação tenha sido eficaz, pois esteve ancorado em referenciais teóricos que empregaram conhecimentos da aprendizagem significativa, envolvendo os adultos na construção da soluçáo dos problemas para a aplicação em seus contextos de vida diária, revelando motivação para a aprendizagem.
Apesar dos resultados positivos, algumas limitaçōes foram encontradas ao longo do estudo. Devido à pesquisa ser realizada no ambiente de atuação de cada interlocutor, ocorreram intercorrências, como na casa (telefone, companhia, outro filho), na escola especial (rotina da escola) e na clínica (reuniôes). Outros fatores que limitaram o estudo foram: faltas dos participantes, problemas de saúde da criança (gripes, resfriados) e dificuldade dos interlocutores em utilizar o computador.

Recomenda-se testar os procedimentos de formação dos interlocutores descritos e apresentados no presente estudo com vistas a fornecer contribuições para futuras pesquisas no campo da formação e capacitação de interlocutores para uso da comunicaçáo suplementar e/ou alternativa.

\section{Referências}

ALEGRO, R. C. Conhecimento prévio e aprendizagem significativa de conceitos históricos no ensino médio. 2008. 239 f. Tese (Doutorado em Educação) - Universidade Estadual Paulista, Marília, 2008.

ARAÚJO, R. C. T.; BRACCIALLI, L. M. P.; DELIBERATO, D. A comunicação alternativa como área de conhecimento nos cursos de educação e da saúde. In: CONGRESSO BRASILEIRO DE COMUNICAÇÃO AlternATIVA, 3., 2009, São Paulo. Anais... São Paulo: Memnon Ediçōes Científicas, 2009. p. 275-284.

BAX, M. et al. Proposed definition and classification of cerebral palsy, April 2005. Developmental Medicine \& Child Neurology, London, v. 47, n. 8, p. 571-576, 2005.

BONDY, A.; FROST, L. The picture exchange communication system. Behavior Modification, United States, v. 25, n. 5, p. 725-744, 2001.

BORTAGARAI, F. M.; RAMOS-SOUZA, A. P. Discurso de fisioterapeutas acerca da comunicaçáo com sujeitos com encefalopatia crônica náo progressiva. Fisioterapia em Movimento, Curitiba, v. 25, n. 4, p. 737-746, 2012.

BRASIL. Ministério da Saúde. Secretaria de Atençáo à Saúde. Diretrizes de atenção à pessoa com paralisia cerebral. Brasília: Secretaria de Atenção à Saúde, 2013. Disponível em: <http://bvsms.saude.gov.br/bvs/publicacoes/diretrizes_atencao_paralisia_cerebral.pdf>. Acesso em: 20 maio 2015

CESA, C. C.; MOTA, H. B. Comunicaçấo aumentativa e alternativa: panorama dos periódicos brasileiros. Revista CEFAC, São Paulo, v. 17, n. 1, p. 264-269, 2015.

COSTIGAN, F. A.; LIGHT, J. Effect of seated position on upper-extremity access to augmentative communication for children with cerebral palsy: preliminary investigation. American Journal of Occupational Therapy, New York, v. 64, n. 4, p. 596-604, 2010. http://dx.doi. org/10.5014/ajot.2010.09013. 
DELIBERATO, D. Caracterização das habilidades expressivas de um aluno usuário de comunicação alternativa durante intervenção fonoaudiológica. 2010. 178 f. Tese (Livre-Docência) - Universidade Estadual Paulista, Marília, 2010.

DELIBERATO, D.; SAMESHIMA, F. S. Habilidades comunicativas utilizadas por um grupo de alunos não falantes durante atividade de jogo. In: NUNES, L. R. O. P.; PELOSI, M. B.; GOMES, M. R. (Org.). Um retrato da comunicação alternativa no Brasil: relatos de pesquisas e experiências. Rio de Janeiro: 4 Pontos Estúdio Gráfico e Papéis, 2007. p. 118-122.

DUTRA, M. I.; FAGUNDES, S. L.; SCHIRMER, C. R. Comunicação para todos - em busca da inclusão social e escolar. In: NUNES, L. R. O. P.; PELOSI, M. B.; GOMES, M. R. (Org.). Um retrato da comunicação alternativa no Brasil: relatos de pesquisas e experiências. Rio de Janeiro: 4 Pontos Estúdio Gráfico e Papéis, 2007. p. 130-135.

KENNEDY, P. Navigating through transition with individuals with speech disabilities. Perspectives on Augmentative and Alternative Communication, Rockville, v. 19, n. 2, p. 44-50, 2010.

KRÜGER, I. S. et al. Bibliometric analysis of the scientific production on AAC: a survey in Scopus database. In: THE COMMUNICATION MATTERS NATIONAL AAC CONFERENCE, 2015, Leeds. Proceedings... Leeds: University of Leeds, 2015. Disponível em: <http://www.communicationmatters.org.uk/conference-session/2015-bibliometric-analysis $>$. Acesso em: 20 maio 2015.

LAW, M. et al. Medida Canadense de Desempenho Ocupacional. Belo Horizonte: Editora UFMG, 2009.

LIGHT, J.; MCNAUGHTON, D. The changing face of augmentative and alternative communication: past, present, and future challenges. Augmentative and Alternative Communication, Abingdon, v. 28, n. 4, p. $197-$ 204, 2012. https://doi.org/10.3109/07434618.2012.7 37024 .

LIGHT, J.; MCNAUGHTON, D. Putting people first: re-thinking the role of technology in augmentative and alternative communication intervention. Augmentative and Alternative Communication, Abingdon, v. 29, n. 4, p. 299-309, 2013. doi: https://doi.org/10.3109/074346 18.2013 .848935 .

LIGHT, J.; MCNAUGHTON, D. Communicative competence for individuals who require augmentative and alternative communication: a new definition for a new era of communication? Augmentative and Alternative Communication, Abingdon, v. 30, n. 1, p. 1-18, 2014. https://doi.org/10.3109/07434618.2014.885080.

LIGHT, J.; MCNAUGHTON, D. Designing AAC Research and Intervention to Improve Outcomes for Individuals with Complex Communication Needs. Augment Altern Commun., Abingdon, v. 31, n. 2, p. 85-96, 2015. https://doi.org/10.3109/07434618.2015.1036458.
MANZINI, M. G. Efeito de um programa de comunicação alternativa para a capacitaçâo de mães de crianças com paralisia cerebral náo verbal. 2013. 110 f. Dissertação (Mestrado em Educação Especial) - Universidade Federal de São Carlos, São Carlos, 2013.

MANZINI, M. G. Programa de Comunicação Alternativa para crianças com paralisia cerebral não verbais em contextos de vida diária. Sáo Carlos: UFSCar, 2015. Relatório FAPESP.

MANZINI, M. G.; ASSIS, C. P.; MARTINEZ, C. M. S. Contribuiçóes da Terapia Ocupacional na área da comunicação suplementar e/ou alternativa: análise de periódicos da Terapia Ocupacional. Cadernos de Terapia Ocupacional da UFSCar, São Carlos, v. 21, n. 1, p. 59 73, 2013.

MANZINI, M. G.; MARTINEZ, C. M. S.; ALMEIDA, M. A. Programa individualizado de comunicação alternativa para mães de crianças com paralisia cerebral não oralizadas. Distúrbios da Comunicação, São Paulo, v. 27, n. 1, p. 26-38, 2015.

MINAYO, M. C. S. O desafio do conhecimento: pesquisa qualitativa em saúde. São Paulo: Hucitec, 2013.

NUNES, L. R. O. P.; DELGADO, S. M. M.; WALTER, C. C. F. o que dizem as famílias e os profissionais sobre a comunicação alternativa. In: NUNES, L. R. D. P.; PELOSI, M. B.; WALTER, C. C. F. (Org.). Compartilhando experiências: ampliando a comunicação alternativa. Marília: ABPEE, 2011. p. 41-55.

OMOTE, S. A deficiência e a família. In: MARQUEZINE, M. C. et al. (Org.). O papel a família junto ao portador de necessidades especiais. Londrina: Eduel, 2003. p. 15-18.

PELOSI, M. B. O papel do terapeuta ocupacional na tecnologia assistiva. Cadernos de Terapia Ocupacional da UFSCar, São Carlos, v. 13, n. 1, p. 39-63, 2005.

PELOSI, M. B. Tecnologias em comunicação alternativa sob o enfoque da terapia ocupacional. In: DELIBERATO, D.; GONÇALVES, M. J.; MACEDO, E. C. (Org.). Comunicação alternativa: teoria, prática, tecnologias e pesquisa. São Paulo: Memnon Ediçóes Científicas, 2009. p. 163-173.

PIRES, S. C. F.; LIMONGI, S. C. O. A família no trabalho de indicação e desenvolvimento do uso de CSA: caso clínico. In: NUNES, L. R. O. P.; PELOSI, M. B.; GOMES, M. R. (Org.). Um retrato da comunicação alternativa no Brasil: relatos de pesquisas e experiências. Rio de Janeiro: 4 Pontos Estúdio Gráfico e Papéis, 2007. p. 313-317.

ROCHA, A. N. D. C.; DELIBERATO, D.; ARAÚJO, R. C. T. Procedimentos para a prescrição dos recursos de tecnologia assistiva para alunos da educação infantil com paralisia cerebral. Revista de Educação Especial, Santa Maria, v. 28, n. 53, p. 691-707, 2015.

ROSENBAUM, P. et al. A report: the definition and classification of cerebral palsy. Developmental Medici- 
ne and Child Neurology. Supplement, United Kingdon, v. 109, p. 8-14, 2007. Disponível em: <http://onlinelibrary.wiley.com/doi/10.1111/j.1469-8749.2007. tb12610.x/pdf>. Acesso em: 21 maio 2015.

SILVA, R. L. M. Um olhar bioecológico sobre os efeitos da comunicação alternativa na interação professor-aluno com paralisia cerebral. 2011. 189 f. Dissertação (Mestrado em Teoria e Pesquisa do Comportamento) - Universidade Federal do Pará, Belém, 2011.

TETZCHNER, S. V. Suporte ao desenvolvimento da comunicação suplementar alternativa. In: DELIBERATO, D.; GONÇALVES, M. J.; MACEDO, E. C. (Org.). Comunicaçấo alternativa: teoria, prática, tecnolo- gias e pesquisa. São Paulo: Memnon Edição Científicas, 2009. p. 14-27.

VIANNA, C. R.; GRECA, L. C. M.; SILVA, R. A. F. Quem são eles? Os alunos da minha sala de aula? In: BRASIL. Secretaria de Educação Básica. Diretoria de Apoio à Gestão Educacional. Pacto Nacional pela Alfabetização na Idade Certa: Educação Inclusiva. Brasília: MEC; SEB, 2014. p. 21-54.

WALTER, C.; ALMEIDA, M. A. Avaliação de um programa de comunicação alternativa e ampliada para mães de adolescentes com autismo. Revista Brasileira de Educação Especial, Marília, v. 16, n. 3, p. 429-446, 2010.

\section{Contribuição dos Autores}

Mariana foi responsável pela coleta e análise dos dados, concepção, elaboração, organização e redação do texto. Bárbara e Gerusa foram responsáveis pela análise dos dados, transcrição das entrevistas e redação do artigo. Claudia foi responsável pela orientação do trabalho e redação do artigo. Todas as autoras aprovaram a versão final do texto.

\section{Fonte de Financiamento}

FAPESP - processo no 2014/ 17741-6.

\section{Notas}

${ }^{1}$ Este estudo apresenta um recorte dos dados da pesquisa de doutorado da primeira autora.

2 Parecer aprovado sob no $922.817 / 2014$.

${ }^{3}$ Por meio do estudo do prontuário, a audição, a visão e a cognição da criança foram constatadas em laudos médicos como normais.

${ }^{4}$ Caso os interlocutores considerassem as figuras do software Boardmaker de difícil compreensão para a criança, a figura poderia ser selecionada no Google ou o objeto pessoal da criança poderia ser fotografado.

${ }^{5}$ Nome fictício do irmão da criança pesquisada. 